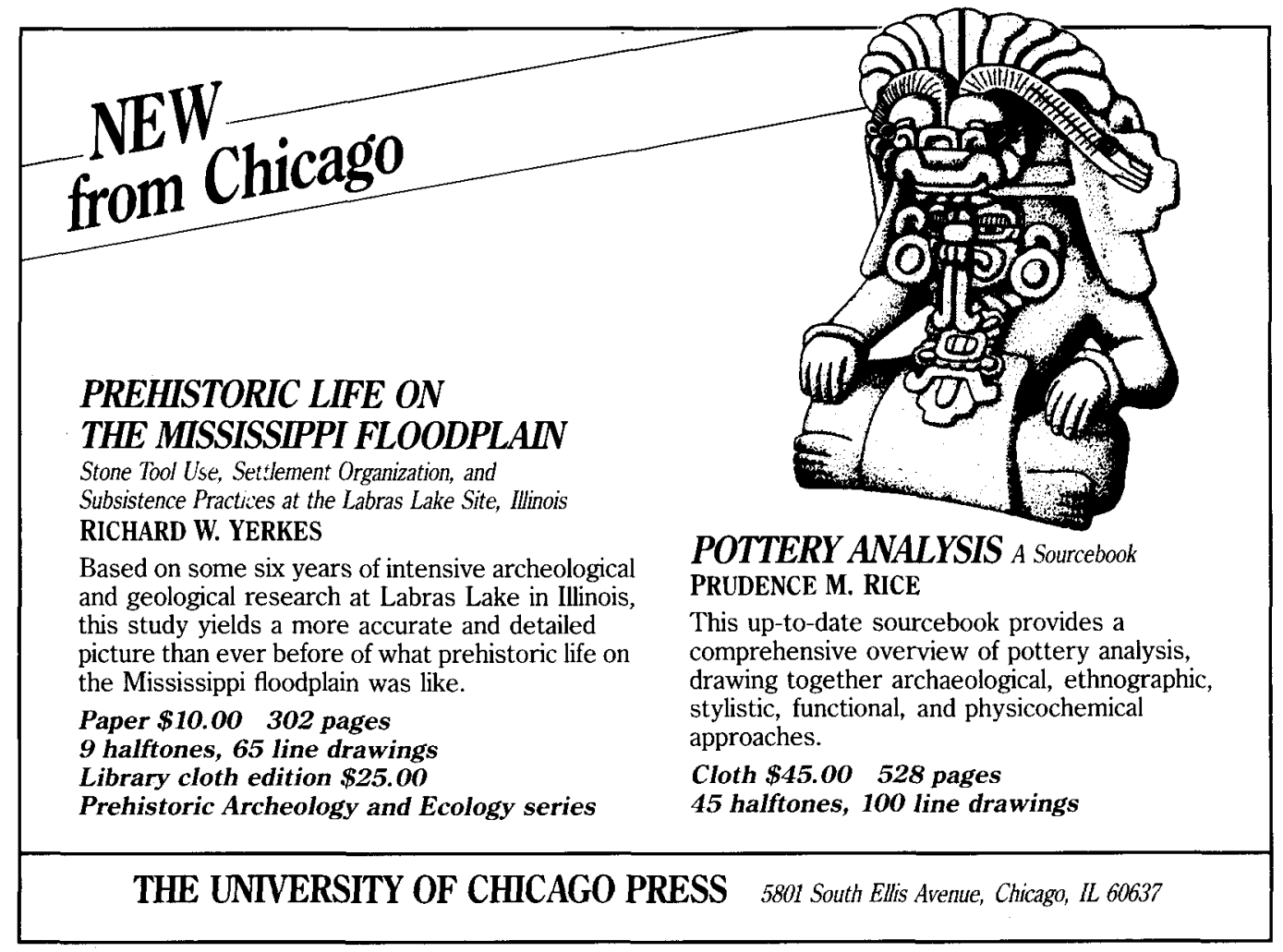

\title{
Evolution of the
} Onondaga Iroquois Accommodating Change, 1500-1655

\section{JAMES W. BRADLEY}

Using both archaeological and historical documents, Bradley examines the Onondaga Iroquois, the central nation of the Iroquois Confederacy, and the way their culture changed as a result of contact with Europeans.

Bradley first traces the origins of the Onondaga. Emphasizing both settlement patterns and the evolution of distinctive artifact forms, he follows the Onondaga through the sixteenth and early seventeenth centuries. He details first the introduction of, and then the steady increase in, European goods. The focus is on how the Onondaga incorporated these foreign materials into their own culture on a conceptual as well as a practical level.

288 pages, photos, maps, figures $\&$ tables, index

Cloth $\$ 24.95$

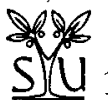




\section{New from Cambridge University Press}

\section{Specialization, Exchange and Complex Societies Elizabeth M. Brumfiel and Timothy Earle, Editors}

This book, the first comparative study of specialized production in prehistoric societies, examines both adaptionist and political approaches to specialization and exchange. Questions are analyzed in the context of ten prehistoric societies with widely varying degrees of complexity.

\section{Re-Constructing Archaeology}

Theory and Practice

\section{Michael Shanks and Christopher Tilley}

The authors develop an alternative philosophical and conceptual basis for a truly social archaeology and follow this with two substantial analyses of material culture - ceramic design in early farming communities in southern Sweden and the design and imagery of beer cans in contemporary Sweden and Britain.

New Studies in Archaeology

\section{Centre and Periphery in the Ancient World Michael Rowlands, Mogens Larsen, and Kristian Kristiansen, Editors}

The contributors examine whether ancient societies were molded over time by the larger system to which they belonged.

Contributors: Colin Haselgrove, Lotte Hedeager, Philip Kohl, Kristian Kristiansen, Mogens Larsen, Mario Liverani, Leon Marfoe, Roger Moorey, Daphne Nash, Michael Rowlands, Carlo Zacagnini.

New Directions in Archaeology

\section{Maya Postclassic State Formation}

Segmentary Lineage Migration in Advancing Frontiers

\section{John Fox}

Fox offers a new view of the crucial Classic-Post Classic transition that determined the shape of the later Maya state. His conclusion, that the inherently fissile nature of segmentary lineages caused the leapfrogging migrations of up to $500 \mathrm{kms}$ observed among the Maya, offers a convincing solution to a problem that has long puzzled scholars.

New Studies in Archaeology

About $\$ 42.50$

\section{Peruvian Prehistory}

\section{Richard W. Keatinge}

"... a valuable overview of recent advances in the field of Andean archaeology"

- John R. Alden, Natural History

Keatinge offers an authoritative survey of the cultural evolution of Peru from the appearance of the first inhabitants around 10,000 B.C. to the arrival of the Spanish in 1534.

Contributors: Richard L. Burger, Claude Chauchat, William J. Conklin, Rosa Fung Pineda, William H. Isbell, Craig Morris, Michael E. Moseley, Patricia Netherly, Jeffrey R. Parsons, J. Scott Raymond.

Cloth about $\$ 39.50 \quad$ Paper about $\$ 11.95$ 


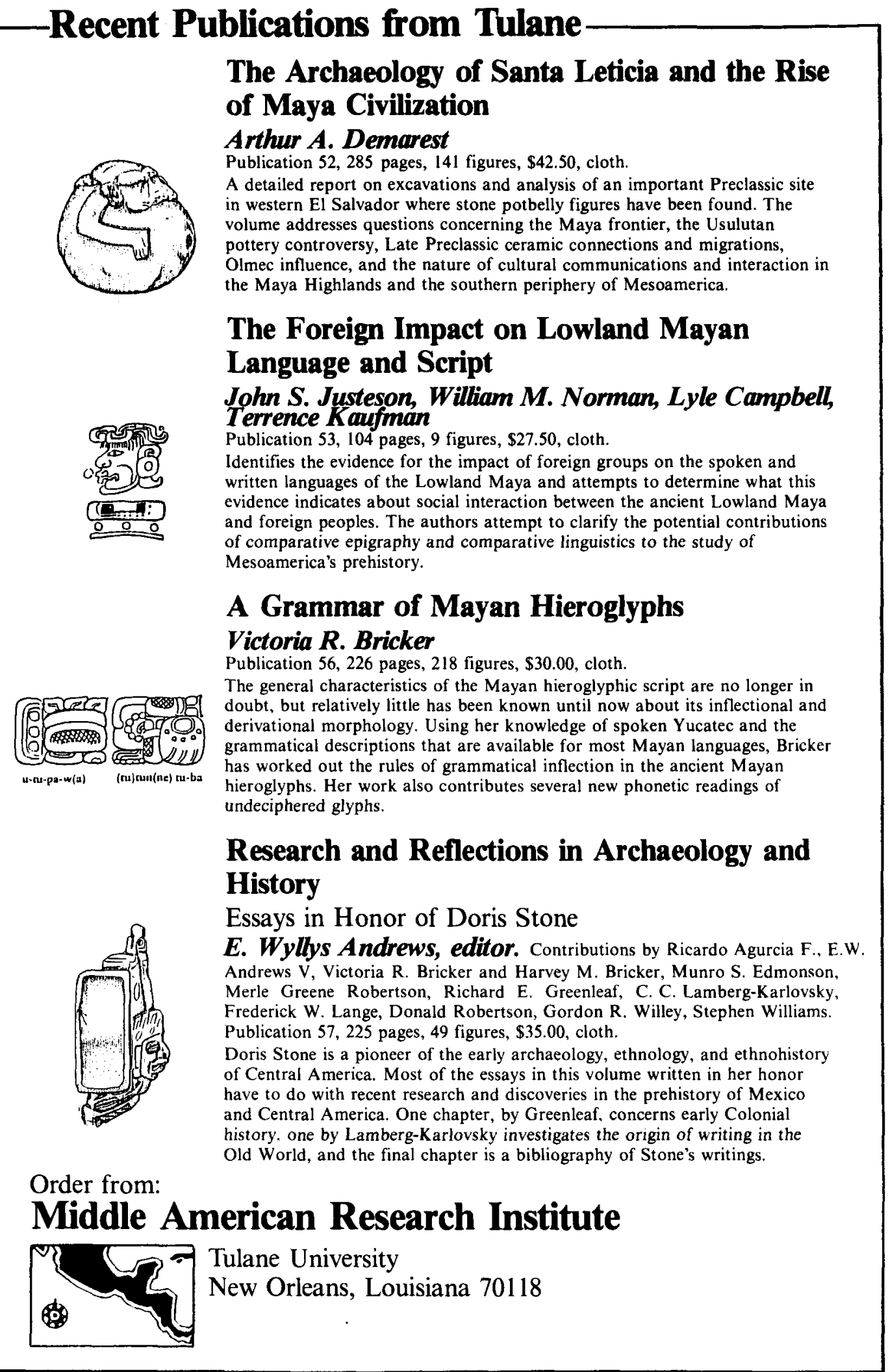




\title{
Windows on the
} Japanese Past:

\section{Studies in Archaeology and Prehistory}

\section{Editor}

\author{
Richard J. Pearson \\ Coeditors \\ Gina Lee Barnes
}

Karl L. Hutterer

"a monumental work . . . As an interested historian, I can think of no comparable book, in any area of Japanese studies, that does so much to record the history of a discipline, to define its current practices, and to outline its 'agenda.',

\section{Mary Elizabeth Berry \\ University of California, Berkeley}

"With publication of Windows on the Japanese Past it is finally possible to present a reasonable course on Japanese prehistory and early history without being a specialist on the subject and without the ability to read Japanese. This will, without doubt, be the book in English on the subject for years to come."

\author{
Wilhelm G. Solheim II \\ University of Hawaii, Manoa \\ $x x+629$ pages, 167 figures, 35 tables, \\ bibliographies, glossary, index \\ Cloth - ISBN 0-939512-23-8, \$48.95 \\ Paper — ISBN 0-939512-24-6, \$27.95
}

Center for Japanese Studies, The University of Michigan 108 Lane Hall, Ann Arbor, MI 48109-1290 


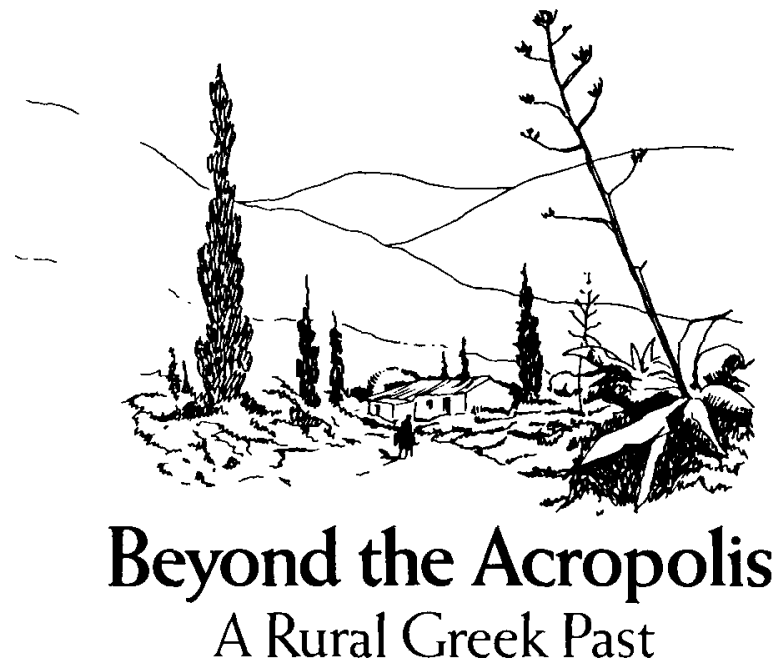

Tjeerd H. van Andel and Curtis Runnels. Beneath the cultural peaks of Ancient Greece lay the basic agricultural economy that made civilization possible. This economy has been mostly ignored by archaeologists, as it was by the ancient Creeks themselves. Based on an interdisciplinary research project in the southern Argolid, this book begins to put flesh to Greek country life, from its earliest beginnings until the recent past. It reveals a sequence of geological, geographic, cultural, and economic images spanning some 50,000 years of human settlement and land use, and vividly shows the interconnection of a landscape and the people who live upon it With 34 illustrations and 26 maps. $\$ 27.50$

\section{The Evolution of Human Societies From Foraging Group to Agrarian State}

Allen W. Johnson and Timothy Earle. By combining an original thesis and a representative body of ethnographic, ethnohistoric, and archaeological data, this ambitious work seeks to describe and explain the evolution of human societiesfrom scattered family groups through local polities to the onset of industrialization. Its emphasis is on the causes, mechanisms, and patterns of cultural evolution, which the authors explain in terms of a coherent theory of the political economy-defined as the mobilization and exchange of goods and services between families. The validity of their theory rests on an extensive documentation that develops the argument through detailed case studies. $\$ 39.50$

\section{$\Xi$ \\ Stanford University Press}

STANFORD, CA 94305 


\title{
53rd ANNUAL MEETING SOCIETY FOR AMERICAN ARCHAEOLOGY
}

\author{
Phoenix Hilton Hotel \\ Phoenix, Arizona \\ Wednesday, April 27-Sunday, May 1, 1988 \\ Annual Meeting Chair: Sylvia W. Gaines, Department of Anthropology, \\ Arizona State University, Tempe, AZ 85287.
}

\section{GUIDELINES FOR CONTRIBUTIONS}

The privilege of participating in the annual meeting as a presenter, chair, or discussant is restricted to paid-up members. However, representatives of other disciplines or archaeologists who are not North American residents may request a waiver of this requirement.

Society policy states that a person may not deliver more than one paper although that person may, at the same meeting, chair a session or serve as junior author of a paper presented by someone else. All presenters, chairs, and discussants are required to pay the established registration fee for the annual meeting; registration fee must accompany the Contributor Index Form. The registration fee requirement may be waived upon written request only for reasons of hardship. Meeting registration fees will be refunded for any paper that is declined.

Complete symposia proposals (with abstracts of papers), abstracts of contributed papers, abstracts of research reports, and abstracts for poster sessions must reach the program chairperson no later than October 1, 1987. All proposals and abstracts must be submitted on appropriate SAA forms, which are mailed to all SAA members with the ballot. In cases of co-authorship of papers, only the presenting author (whether senior or junior author) need submit a Contributor Index Form. Additional forms may be obtained from the Society at its headquarters address.

Because it is no longer possible to accommodate all the individuals wishing to make presentations at the annual meeting, the Program Committee will evaluate each submission for professionalism and redundancy with other submissions. Symposia organizers and authors of contributed papers, research papers, and poster sessions will be notified of the Program Committee's decision to accept or decline the submission by January 15, 1988. Abstracts of all papers and research reports accepted for presentation will be published in the final program. Long abstracts are no longer required.

SYMPOSIA-A symposium consists of a group of papers on a common theme. The symposium topic and the individual papers within it will be reviewed. Changes, such as consolidation of two symposia or changes in the individual papers, may be recommended. Symposia organizers should contact the Program Chair no later than September 1, 1987 in order that the Guidelines for Symposium Organizers and a special symposium form can be sent to them. Complete symposia proposals must be submitted as a package by the symposium organizer(s) and must be received by October 1, 1987. The package must include for every paper presented in the symposium: 2 copies of the SAA Short Abstract Form, 2 copies of the SAA Contributor Index Form, and the meeting registration fee. (The symposium organizer should collect and submit all meeting registration fees for his or her symposium presenters.) The deadline for all submissions is October $1,1987$.

CONTRIBUTED PAPERS (20 minutes)-Contributed papers are to be distinguished from Research Reports in that they generalize, synthesize, or compare and are addressed to problems of theory, method, culture history, or culture process. Contributed papers must follow the same format as the symposia papers, and each proposed presentation must include: 2 copies of the SAA Short Abstract Form, 2 copies of the SAA Contributor Index Form, and the meeting registration fee.

RESEARCH REPORTS (10 minutes) - A research report is an oral presentation that describes the results of a recent field or laboratory research project. Each proposed presentation must include: 2 copies of the SAA Short Abstract Form, 2 copies of the SAA Contributor Index Form, and the meeting registration fee.

POSTER SESSION-Like the research report, the poster session is a description of the results of a recent field or laboratory research project. The poster session is especially appropriate for research results that can be described graphically better than verbally. Each proposed presentation must include: 2 copies of the SAA Short Abstract Form, 2 copies of the SAA Contributor Index Form, and the meeting registration fee.

Please follow these instructions carefully. Incorrect or late submissions can be considered only if space and time allow. All other scheduling and room requests for committee meetings, promotional booths, etc. should be directed to Jerome A. Miller, 1511 K St N.W. Suite 716, Washington, DC 20005. 


\section{CONTENTS}

Editor's Corner

1987 Distinguished Service Award

1987 Fryxell Award for Interdisciplinary Research

\section{ARTICLES}

Estimating Tillage Effects on Artifact Distributions

Economic Specialization and Construction Personnel in Classic Period Copan, Honduras

Conditional Spatial Patterning: Beyond the Nearest Neighbor

Toward a Processual Understanding of the Initial Variant of the Middle Missouri Tradition: The Case of the Mill Creek Culture of Iowa

Architecture as Artifact: Pit Structures and Pueblos in the American Southwest

Obscuring Cultural Patterns in the Archaeological Record: A Discussion from Southwestern Archaeology
W. Raymond Wood 449 450

George H. Odell and Frank Cowan

Elliot M. Abrams

Albertus Voorrips and John M. O'Shea 500

Duane C. Anderson

Patricia A. Gilman

Linda S. Cordell, Steadman Upham, and Sharon L. Brock

\section{REPORTS}

The Work of Metallurgical Artificers at Machu Picchu, Peru

Petrographic Analysis of Basalt Artifacts from Three Aleutian Sites

Diagnostic Opal Phytoliths from Rinds of Selected Cucurbita Species

John W. Rutledge and Robert B. Gordon

Owen $K$. Mason and Jean S. Aigner

Steven R. Bozarth

\section{COMMENTS}

Comment on "Tomato Springs: The Identification of a Jasper Trade and Production Center in Southern California"

Comments on Cottrell's Long Distance Jasper Trade Hypothesis: In Defense of Renfrew's Trade Models

CURRENT RESEARCH, edited by Lynne Goldstein

Plains, Great Lakes

ERRATUM

REVIEWS AND BOOK NOTES, edited by Susan C. Vehik 